American Journal of Applied Sciences 6 (2): 219-223, 2009

ISSN 1546-9239

(C) 2009 Science Publications

\title{
Strength Modeling of High-Strength Concrete with Hybrid Fibre Reinforcement
}

\author{
A. Ravichandran, K. Suguna and P.N. Ragunath \\ Department of Structural Engineering, \\ Annamalai University Annamalainagar-608002, India
}

\begin{abstract}
The low tensile strength and limited ductility, the unavoidable deficiency, of concrete can be overcome by the addition of fibres. High strength concrete (HSC) of $60 \mathrm{MPa}$ containing hybrid fibres, combination of steel and polyolefin fibres, at different volume fraction of $0.5,1.0,1.5$ and $2.0 \%$ were compared in terms of compressive, splitting tensile strength and flexural properties with HSC containing no fibres. Test results showed that the fibres when used in hybrid form could result in enhanced flexural toughness compared to steel fibre reinforced concrete [HSFRC]. The compressive strength of the fibre-reinforced concrete reached maximum at $1.5 \%$ volume fractions and the splitting tensile strength and modulus of rupture improved with increasing volume fraction. Strength models were established to predict the compressive and splitting tensile strength and modulus of rupture of the fibre-reinforced concrete. The models give prediction matching the measurements.
\end{abstract}

Key words: HSFRC, HYFRC, polyolefin fibre, steel fibre

\section{INTRODUCTION}

With the development of high grade cement and availability of proper mineral admixtures and chemical admixtures, it has become quite common to adopt concrete with compressive strength of $60 \mathrm{MPa}$ and above. The resulting structures are slender. Development of high strength concrete has made it possible to build taller and long span structures in concrete that was not otherwise possible ${ }^{[1,2]}$. But it has been proved that the comparatively higher compressive strength of HSC is an attractive profit from engineering characteristics and economic point of view whereas, the strength behaves against the ductility of concrete by welcoming brittleness pronouncedly ${ }^{[3]}$. To improve the ductility of HSC, a strategy is to introduce steel or polymeric fibres in HSC which results in development of near isotropic material with reasonable tensile strength and greater toughness which prevents the initiation and propagation of cracks $^{[4-8]}$.

It has also been shown recently ${ }^{[9-12]}$ that by using the concept of hybridization with two different fibres incorporated in a cement matrix, the hybrid composite can offer more attractive engineering properties because the presence of one fibre enables the more efficient utilization of the potential properties of the other fibre. However, the hybrid composites studied by previous researchers were focused on hybridization of steel, polypropylene and carbon fibres. The mechanical properties of hybridization of steel and polyolefin fibres in HSC at different volume fraction $(0.5,1.0,1.5$ and $2.0 \%$ ) have been studied previously are available limited. Therefore the objective of this research is to determine the basic properties of hybrid fibre reinforced high strength concrete in terms of compressive, splitting tensile and flexural tests in comparison with the plain high-strength counter part and establishes models for predicting the behaviour of HSFRC and HYFRC under compression, splitting tension and flexure.

\section{MATERIALS AND METHODS}

The cement used in concrete mixes was ordinary Portland cement 53 grade as per IS 12269-1987. The sand used was local river sand with specific gravity of 2.54. The coarse aggregate was crushed stone with size of $20 \mathrm{~mm}$ and $10 \mathrm{~mm}$ and specific gravity of 2.67 . Silica fume used was a commercially available CONPLAST (MS) in densified form which improved concrete properties in fresh and hardened states. To improve the workability of concrete, a high-range water-reducing admixture [hyper-plasticizer] was used during mixing operations.

The properties of the steel and polyolefin fibres are shown in Table 1 and the concrete mix proportions used in the test program are presented in Table 2.

Corresponding Author: Ravichandran A., Department of Structural Engineering,

Annamalai University Annamalainagar-608002, India Tel: +919443577120 
Preparation of test specimens: In the preparation of concrete, the constituent materials were initially mixed without fibres. The fibres were then added in small amounts to avoid balling of fibres and to produce concrete with uniform material consistency and good workability. The steel fibre reinforced concrete and hybrid fibre reinforced concrete [combination of steelpolyolefin fibres] at different volume fraction of 0.5 , $1.0,1.5$ and $2.0 \%$ specimens were placed into moulds and a vibrator was used to decrease the amount of air bubbles. The specimens were remolded after $24 \mathrm{~h}$ and then placed in a curing tank for 28 days and the

Table 1 Properties of Fibres used

\begin{tabular}{lll}
\hline & Fibre properties & \\
& - & \\
Fibre details & Polyolefin & Steel \\
\hline Length $(\mathrm{mm})$ & 48 & 30 \\
Shape & Straight & Hooked at ends \\
& $\overline{1.22 \times 0.732 \mathrm{~mm}}$ & $0.5 \mathrm{~mm}$ \\
Size/Diameter $(\mathrm{mm})$ & 39.34 & 60 \\
Aspect Ratio & 920 & 7850 \\
Density $\left(\mathrm{kg} \mathrm{m}^{-3}\right)$ & $0.90-0.92$ & - \\
Specific gravity & 6 & 210 \\
Young's modulus $(\mathrm{GPa})$ & 550 & 532 \\
Tensile strength $(\mathrm{MPa})$ & 55 \\
\hline
\end{tabular}

Table 2: Concrete mix proportions used in the testing program

\begin{tabular}{ll}
\hline Material & Quantity \\
\hline $53 \mathrm{Grade} \mathrm{cement}\left(\mathrm{Kg} \mathrm{m}^{-3}\right)$ & 450 \\
Sand $\left(\mathrm{Kg} \mathrm{m}^{-3}\right)$ & 780 \\
Coarse aggregate $\left(\mathrm{Kg} \mathrm{m}^{-3}\right)$ & \\
$20 \mathrm{~mm}$ size & 680 \\
$10 \mathrm{~mm}$ size & 450 \\
Water $\left(\mathrm{Kg} \mathrm{m}{ }^{-3}\right)$ & 160 \\
Silica fume $\left(\mathrm{Kg} \mathrm{m}^{-3}\right)$ & 25 \\
Hyper plasticizer $\left(\mathrm{Kg} \mathrm{m}^{-3}\right)$ & 25 \\
Slump & $100 \mathrm{~mm}$ \\
\hline
\end{tabular}

specimens were removed from curing tank and allowed to air dry $12 \mathrm{~h}$ prior to test.

Test methods: For each mixture, $150 \times 300 \mathrm{~mm}$ cylindrical specimens and $100 \times 100 \times 500 \mathrm{~mm}$ beams were prepared. The compressive strength test was carried out on $150 \times 300 \mathrm{~mm}$ cylinder specimens as per ASTM C 39. The cylinders were loaded, in a compression testing machine at the rate of $0.3 \mathrm{MPa} / \mathrm{s}$ until failure.

The splitting tensile test, on the cylinder specimens, was conducted in accordance with ASTM C 496. In the test, the load was applied continuously at the rate of $0.9 \mathrm{MPa} / \mathrm{min}$. until failure.

The flexural strength (modulus of rupture, MOR) test were conducted on prismatic beam specimens under third-point loading, in accordance with ASTM C 78 for flexural strength of fibreous concrete and ASTM C 1108 for the flexural toughness of fibre reinforced concrete. The beam was loaded gradually to increase the deflection at constant rate.

\section{RESULTS AND DISCUSSION}

Table 3 presents the strength test results on HSFRC, HYFRC and HSC. The compressive strength, splitting tensile strength and modulus of HSFRC and HYFRC improved to different extent in response to the fibre volume fraction.

Compressive strength: Figure 1 shows the effect of fibre volume on compressive strength of HSC of 60 MPa. The compressive strength development of HSC and of HSFRC and HYFRC provided an improvement

Table 3: Mechanical properties of fibre-reinforced concretes

\begin{tabular}{|c|c|c|c|c|c|c|c|c|}
\hline \multicolumn{3}{|c|}{ Fibre volume (\%) } & \multicolumn{2}{|c|}{ Compressive strength (MPa) } & \multicolumn{2}{|c|}{ Splitting tensile strength (MPa) } & \multicolumn{2}{|c|}{ Modulus of rupture (MPa) } \\
\hline Steel & PO & Total & $\begin{array}{l}\text { Measured } \\
\text { value }\end{array}$ & $\begin{array}{l}\text { Strength } \\
\text { effectiveness (\%) }\end{array}$ & $\begin{array}{l}\text { Measured } \\
\text { value }\end{array}$ & $\begin{array}{l}\text { Strength } \\
\text { effectiveness (\%) }\end{array}$ & $\begin{array}{l}\text { Measured } \\
\text { value }\end{array}$ & $\begin{array}{l}\text { Strength } \\
\text { effectiveness (\%) }\end{array}$ \\
\hline 0.0 & 0.0 & 0.0 & 61.2 & 0.00 & 4.86 & 0.00 & 7.30 & 0.00 \\
\hline 0.5 & 0.0 & 0.5 & 63.5 & 3.76 & 7.67 & 57.82 & 9.60 & 31.51 \\
\hline 0.4 & 0.1 & 0.5 & 62.2 & 1.63 & 7.90 & 62.55 & 9.72 & 33.15 \\
\hline 0.3 & 0.2 & 0.5 & 61.6 & 0.65 & 7.39 & 52.06 & 9.35 & 28.08 \\
\hline 1.0 & 0.0 & 1.0 & 67.1 & 9.64 & 9.90 & 103.70 & 11.80 & 61.64 \\
\hline 0.8 & 0.2 & 1.0 & 66.3 & 8.33 & 10.00 & 105.76 & 12.00 & 64.38 \\
\hline 0.6 & 0.4 & 1.0 & 63.1 & 3.10 & 8.90 & 83.13 & 11.25 & 54.11 \\
\hline 1.5 & 0.0 & 1.5 & 69.9 & 14.20 & 11.26 & 131.69 & 12.89 & 76.58 \\
\hline 1.2 & 0.3 & 1.5 & 67.5 & 10.30 & 11.45 & 135.60 & 13.00 & 78.08 \\
\hline 0.9 & 0.6 & 1.5 & 65.2 & 6.54 & 10.80 & 122.22 & 12.54 & 71.78 \\
\hline 2.0 & 0.0 & 2.0 & 69.8 & 14.10 & 11.70 & 140.74 & 13.10 & 79.45 \\
\hline 1.6 & 0.4 & 2.0 & 69.2 & 13.10 & 12.50 & 157.20 & 13.80 & 89.04 \\
\hline 1.2 & 0.8 & 2.0 & 68.8 & 12.40 & 11.64 & 139.51 & 13.16 & 80.27 \\
\hline
\end{tabular}

Strength effectiveness $=\frac{\text { HSFRC }(\text { or }) \text { HYFRC strength-HSC value strength }}{\text { HSC strength }} \times 100 \%$ 
at each volume fraction. The compressive strength of HSFRC ranged from $3.76-14.1 \%$ at the volume fraction of $0.5-2.0 \%$ and no significant improvement at $2.0 \%$ volume fraction of steel fibres compared to $1.5 \%$ volume fraction. The compressive strength improvement of HYFRC ranged from 0.65-13.1\%. The improvements in compressive strength of HYFRC have no significant effect compared to HSC with steel fibres.

Following from the compressive strength test results, the compressive strength $\mathrm{f}_{\mathrm{c}}$ of HSFRC and HYFRC was predicted in terms of fibre volume fraction $\mathrm{V}_{\mathrm{f}}$ as

$$
\mathrm{f}^{\prime}{ }_{\mathrm{c}}(\mathrm{MPa})=\mathrm{A}+\mathrm{BV}_{\mathrm{f}}+\mathrm{CV}^{2}{ }_{\mathrm{f}}
$$

and applying regression analysis gave

$$
\mathrm{f}^{\prime}{ }_{\mathrm{c}}(\mathrm{MPa})=59.946+7.97 \mathrm{~V}_{\mathrm{f}}-1.336 \mathrm{~V}_{\mathrm{f}}^{2}
$$

The compressive strength predictions using Eq. 2 matching with measurements and prediction error is below $2.09 \%$ as shown in Table 4.

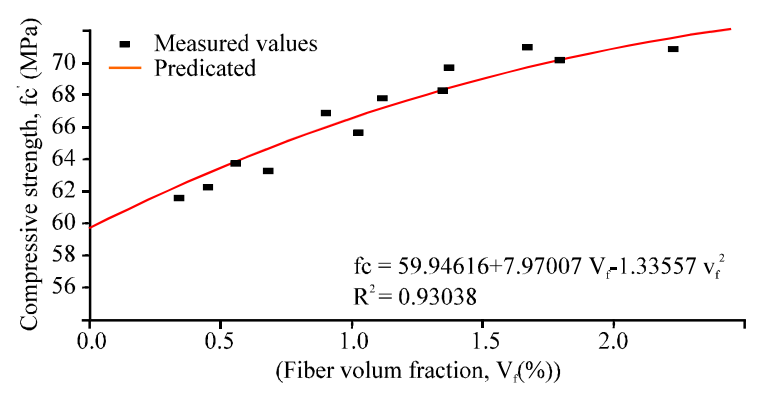

Fig. 1: Effect of fiber volume on compressive strength
At $\mathrm{V}_{\mathrm{f}}=0 \%$, Eq. 2 gives the

$\mathrm{f}^{\prime}{ }_{\mathrm{c}}$ value of HSC equal to $59.946 \mathrm{MPa}$ which is

$\mathrm{f}^{\prime}{ }_{\mathrm{c}}$ value of concrete used in the study.

Splitting tensile strength: The splitting tensile strength of all the fibreous concrete in this investigation was significantly higher than of plain concrete even at volume fraction as low as $0.5 \%$. The development of splitting tensile strength of HSFRC and HYFRC at various volume fractions is shown in Fig. 2 Compared to HSC, the strength improved with increasing the volume fraction. From the strength effectiveness in Table 3, the improvement started from $57.82-140.74 \%$ at the volume fraction of $0.5-2.0 \%$ in case of HSFRC and $62.55-157.20 \%$ in case of HYFRC.

The splitting tensile strength of HSFRC and HYFRC were predicted using the measured values and the fibre volume fraction of $\mathrm{V}_{\mathrm{f}}$

$$
\mathrm{f}^{\prime}{ }_{\mathrm{sp}}(\mathrm{MPa})=\mathrm{A}+\mathrm{BV}_{\mathrm{f}}+\mathrm{CV}_{\mathrm{f}}^{2}
$$

and applying regression analysis gave

$$
\mathrm{f}^{\prime}{ }_{\mathrm{sp}}(\mathrm{MPa})=4.8488+8.07901 \mathrm{~V}_{\mathrm{f}}-2.28909 \mathrm{~V}_{\mathrm{f}}^{2}
$$

At $\mathrm{V}_{\mathrm{f}}=0 \%$, Eq. (4) gives the value of $\mathrm{f}^{\prime}{ }_{\mathrm{sp}}$ of HSC equal to $4.8488 \mathrm{MPa}$ equal to that given by $0.59 \sqrt{ } \mathrm{f}_{\mathrm{c}}{ }_{\mathrm{c}}=$ $0.59 \sqrt{60}$, as per ACI $363 \mathrm{R}-93$ (reapproved 1997). The predicted values matching the measurement and prediction error is below $5.656 \%$ as shown in Table 4 .

Modulus of rupture: The MOR for HSFRC and HYFRC is shown in Fig. 3. The strength effectiveness

\begin{tabular}{|c|c|c|c|c|c|c|c|c|c|c|c|}
\hline \multicolumn{3}{|c|}{ Fibre volume fraction $\mathrm{V}_{\mathrm{f}}(\%)$} & \multicolumn{3}{|c|}{ Compressive strength } & \multicolumn{3}{|c|}{ Splitting tensile strength } & \multicolumn{3}{|c|}{ Modulus of rupture } \\
\hline Steel & $\mathrm{PO}$ & Total & $\begin{array}{l}\text { Measured } \\
\text { (MPa) }\end{array}$ & $\begin{array}{l}\text { Predicted } \\
(\mathrm{MPa})\end{array}$ & $\begin{array}{l}\text { Prediction } \\
\text { error }(\%)\end{array}$ & $\begin{array}{l}\text { Measured } \\
\text { (MPa) }\end{array}$ & $\begin{array}{l}\text { Predicted } \\
\text { (MPa) }\end{array}$ & $\begin{array}{l}\text { Prediction } \\
\text { error }(\%)\end{array}$ & $\begin{array}{l}\text { Measured } \\
\text { (MPa) }\end{array}$ & $\begin{array}{l}\text { Predicted } \\
\text { (MPa) }\end{array}$ & $\begin{array}{l}\text { Prediction } \\
\text { error }(\%)\end{array}$ \\
\hline 0.0 & 0.0 & 0.0 & 61.20 & 59.95 & -2.09 & 4.86 & 4.85 & -0.23 & 7.30 & 7.04 & -3.67 \\
\hline 0.5 & 0.0 & 0.5 & 63.50 & 63.60 & 0.15 & 7.67 & 8.32 & 7.77 & 9.60 & 10.13 & 5.25 \\
\hline 0.4 & 0.1 & 0.5 & 62.20 & 62.94 & 1.18 & 7.90 & 7.73 & -2.17 & 9.72 & 9.61 & -1.13 \\
\hline 0.3 & 0.2 & 0.5 & 61.60 & 62.26 & 1.06 & 7.39 & 7.10 & -4.02 & 9.35 & 9.05 & -3.29 \\
\hline 1.0 & 0.0 & 1.0 & 67.10 & 66.58 & -0.78 & 9.90 & 10.64 & 6.94 & 11.80 & 12.20 & 3.29 \\
\hline 0.8 & 0.2 & 1.0 & 66.30 & 65.52 & -1.19 & 10.00 & 9.88 & -1.17 & 12.00 & 11.53 & -4.08 \\
\hline 0.6 & 0.4 & 1.0 & 63.10 & 64.32 & 1.90 & 8.90 & 8.93 & 0.37 & 11.25 & 10.68 & -5.33 \\
\hline 1.5 & 0.0 & 1.5 & 69.90 & 68.90 & -1.46 & 11.26 & 11.82 & 4.71 & 12.89 & 13.25 & 2.74 \\
\hline 1.2 & 0.3 & 1.5 & 67.50 & 67.63 & 0.19 & 11.45 & 11.27 & -1.60 & 13.00 & 12.76 & -1.84 \\
\hline 0.9 & 0.6 & 1.5 & 65.20 & 66.13 & 1.41 & 10.80 & 10.33 & -4.52 & 12.54 & 11.93 & -5.12 \\
\hline 2.0 & 0.0 & 2.0 & 69.80 & 70.54 & 1.05 & 11.70 & 11.85 & 1.27 & 13.10 & 13.29 & 1.40 \\
\hline 1.6 & 0.4 & 2.0 & 69.20 & 69.32 & 0.17 & 12.50 & 11.92 & -4.84 & 13.80 & 13.35 & -3.38 \\
\hline 1.2 & 0.8 & 2.0 & 68.80 & 67.72 & -1.59 & 11.64 & 11.32 & -2.83 & 13.16 & 12.81 & -2.74 \\
\hline
\end{tabular}
in Table 3 indicates that MOR values of all fibreous concrete were significantly higher than of high strength

Table 4: Comparison of predicted and measured values for compressive and splitting tensile strength and modulus of rupture

Prediction error $=\frac{\text { Predicted value-measured value }}{\text { Measured value }} \times 100 \%$ 
Am. J. Applied Sci., 6 (2): 219-223, 2009

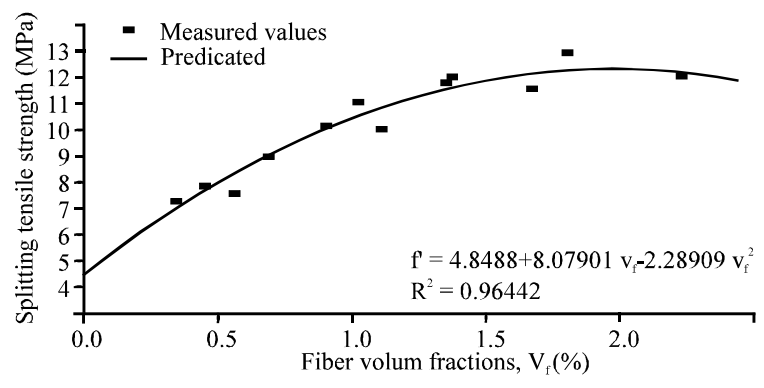

Fig. 2: Effect of fiber volume on splitting tensile strength

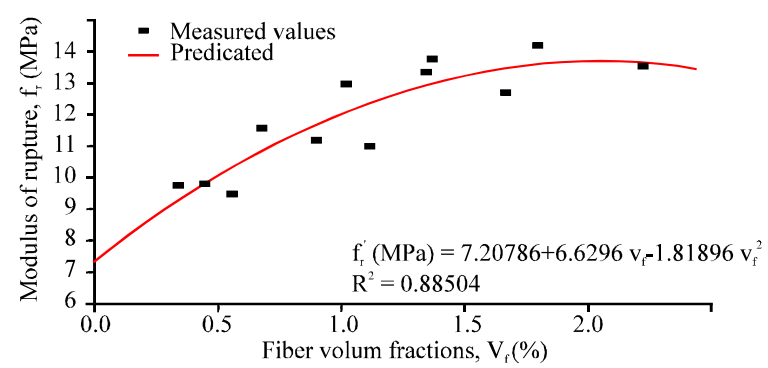

Fig. 3: Effect of fiber volume on modulus of rupture

control concrete even at volume fraction as low as $0.5 \%$. The development of flexural strength of HSFRC and HYFRC at various volume fractions is shown in Fig. 3, compared to HSC. The strength improved with increasing the volume fraction. From the strength effectiveness in Table 3, the improvement started from $31.51-79.45 \%$ at the volume fraction of $0.5-2.0 \%$ incase of HSFRC 28.08-89.04\% incase of HYFRC.

The MOR of HSFRC and HYFRC were predicted using measured values of flexural strength and fibre volume fraction $V_{\mathrm{f}}$.

$$
\mathrm{f}^{\prime}{ }_{\mathrm{r}}(\mathrm{MPa})=\mathrm{A}+\mathrm{BV}_{\mathrm{f}}+\mathrm{CV}^{2}{ }_{\mathrm{f}}
$$

and applying regression analysis gave

$$
\mathrm{f}_{\mathrm{r}}^{\prime}(\mathrm{MPa})=7.20786+6.6296 \mathrm{~V}_{\mathrm{f}}-1.81896 \mathrm{~V}_{\mathrm{f}}^{2}
$$

at $\mathrm{Vf}=0 \%$ Equ. (6) gives the value of $\mathrm{f}{ }_{\mathrm{r}}=7.20786$ $\mathrm{MPa}$ of HSC equal to that given by $0.94 \sqrt{ } \mathrm{f}^{\prime}{ }_{\mathrm{c}}=0.94 \mathrm{~V}$ 60 as per ACI 363R-93 (reapproved 1997). The modulus of rupture predicted matching the measured value and prediction error run below $5.25 \%$ as shown in Table 4.

The comparison of Predicted values by regression analysis and Measured Values for Compressive and Splitting Tensile Strength and Modulus of Rupture of HSFRC and HYFRC are presented in Table 4.

\begin{tabular}{|c|c|c|c|c|c|}
\hline \multicolumn{3}{|c|}{ Fibre volume fraction $\mathrm{V}_{\mathrm{f}}(\%)$} & \multicolumn{3}{|c|}{ Toughness index } \\
\hline Steel & $\mathrm{PO}$ & Total & $\mathrm{I}_{5}$ & $\mathrm{I}_{10}$ & $\mathrm{I}_{30}$ \\
\hline 0.0. & 0.0 & 0.0 & 3.16 & 5.89 & 9.95 \\
\hline 0.5 & 0.0 & 0.5 & 4.12 & 8.25 & 26.88 \\
\hline 0.4 & 0.1 & 0.5 & 4.23 & 8.74 & 28.94 \\
\hline 0.3 & 0.2 & 0.5 & 4.18 & 8.79 & 26.98 \\
\hline 1.0 & 0.0 & 1.0 & 4.46 & 9.18 & 29.56 \\
\hline 0.8 & 0.2 & 1.0 & 4.65 & 9.35 & 30.23 \\
\hline 0.6 & 0.4 & 1.0 & 4.45 & 9.25 & 29.52 \\
\hline 1.5 & 0.0 & 1.5 & 5.35 & 11.75 & 33.50 \\
\hline 1.2 & 0.3 & 1.5 & 5.75 & 12.65 & 35.72 \\
\hline 0.9 & 0.6 & 1.5 & 5.65 & 12.35 & 34.15 \\
\hline 2.0 & 0.0 & 2.0 & 7.25 & 15.23 & 39.85 \\
\hline 1.6 & 0.4 & 2.0 & 7.78 & 16.25 & 40.23 \\
\hline 1.2 & 0.8 & 2.0 & 7.63 & 15.72 & 39.95 \\
\hline
\end{tabular}

Table 5: Flexural toughness indices

Flexural toughness: The toughness of fibre-reinforced concrete can be considered as their energy absorption capacity, which is usually characterized by some portion of the area under the load-deflection curve obtained during flexure test. The flexural toughness indices may be calculated as the ratio of the area under the load- deflection curve for the fibreous concrete to specified endpoints, to the area up to first-crack load, as shown in ASTM C 1018 or to the area obtained for the matrix without fibres.

Three indices defined in ASTM C 1018 are obtained by dividing the area under the load-deflection curve, determined at a deflection that is a multiple of the first-crack deflection, by the area under the curve up to the first-crack. $I_{5}$ is determined at a deflection 3 times the first-crack deflection, $\mathrm{I}_{10}$ is determined at 5.5 and $\mathrm{I}_{30}$ and at 15.5 times the first-crack deflection. These indices increased their values with increasing volume fraction. The $\mathrm{I}_{5}, \mathrm{I}_{10}$ and $\mathrm{I}_{30}$ indexes are presented in Table 5. Toughness indices are higher for highstrength hybrid fibreous concrete than for high-strength concrete with steel fibres at each volume fraction.

\section{CONCLUSIONS}

There is no significant improvement in compressive strength of HSFRC and HYFRC. Splitting tensile and flexural strength of HSFRC and HYFRC both improved significantly compared to HSC.

The strength effectiveness showed at each volume fraction a maximum for splitting tensile strength, followed by modulus of rupture and compressive strength.

The flexural toughness of HSC improved with addition of fibres at various volume fractions. The flexural toughness of HSC containing fibres in hybrid form observed to have more than the HSFRC. 
It is concluded from this investigation that the use of $80 \%$ steel fibres and $20 \%$ polyolefin fibres at each volume fraction gave optimism mechanical properties. At hybrid fibre of $2.0 \%$ volume fraction with $80-20 \%$ steel-polyolefin combination have more significant effect on mechanical properties.

Strength models established by regression analysis give predictions matching the measurements of mechanical properties.

\section{REFERENCES}

1. Swamy, R.N., 1987. High- Strength ConcreteMaterial Properties and Structural Behaviors. ACI SP-87, Detroit: American Concrete Institute, pp: 110-146.

2. Rabbat, B.G. and H.G. Russell, 1982. Optimized Sections for Precast, Pre-Stressed Bridge Girders. Research and Development Bulletin No. RD080.01E, Portland Cement Association, Skokie, pp: $10-15$.

3. Tasdemir, C., M.A. Tasdemir, F.D. Lydon, B.I.G. Barr, 1996. Effects of silica fume and aggregate size of the brittleness of concrete. Cement Concrete Res., 26 (1): 63-68.

4. Hsu, L.S. and T. Hsu, 1994. Stress strain behavior of steel-fiber high-strength concrete under compression. ACI Struct. J., 91 (4): 448-457.

5. Chunxiang, Q. and I. Patnaikuni, 1999. Properties of high-strength steel fibre-reinforced concrete beams in bending. Cement Concrete Composites, 21 (1): 73-81.
6. Song, P.S. and S. Hwang, 2004. Mechanical properties of high-strength steel fiber-reinforced concrete. Construct. Build. Mater., 18: 669-673.

7. Alhozaimy, A.M., P. Soroushian and F. Mirza, 1996. Mechanical properties of polypropylene fiber reinforced concrete and the effects of pozzolanic materials. Cement Concrete Composites, 18: 85-92.

8. Song, P.S., J.C. Wu, S. Hwang and B.C. Sheu, 2005. Statistical analysis of impact strength and strength reliability of steel-polypropylene hybrid fiber-reinforced concrete. Construct. Build. Mater., 19: 1-9.

9. Xu, G. and D.J. Hannant, 1992. Flexural behavior of combined polypropylene network and glass fiber reinforced cement. Cement Concrete Composites 14 (1): 51-61.

10. Kakemi, M. and D.J. Hannant, 1995. Mathematical model for tensile behavior of hybrid continuous fiber. Cement Composites, 26 (9): 637-643.

11. Mobasher, B. and C.Y. Li, 1996. Mechanical properties of hybrid cement-based composites. ACI Mater. J.. 93 (3): 284-292.

12. Wu Yao, Jie Li and Keru Wu, 2003. Mechanical properties of hybrid fiber-reinforced concrete at low fiber volume fraction. Cement Concrete Res., 33: 27-30. 